\title{
Tackling youth mental health inequities: Opportunities and challenges of eHealth
}

\author{
Johanna Sam
}

\section{University of British Columbia}

Mental illness is a large disease burden for youth across the globe, with mental health problems affecting $10-20 \%$ of youth in Canada. ${ }^{1,2}$ Currently, 3.2 million Canadian youth, ages 12-19, are vulnerable to developing a mental illness, and many do not receive mental health services, such as counselling or psychotherapy. ${ }^{2}$ Moreover, research shows that mental health promotion initiatives, such as educational resources promoting healthy behaviour, can strengthen personal wellbeing with concrete, positive outcomes for youth. ${ }^{2}$ As young Canadians integrate online activities into their lives, the use of the Internet, computers, mobile phones, and related technology offers an innovative and cost-effective opportunity to engage youth in mental health services and promotion. ${ }^{1}$ eHealth is an emerging field, which brings together the use of technology, the coordination of online health systems, and the delivery of health services and promotion. ${ }^{1}$ The present paper considers the potential for eHealth strategies to advance accessibility and equity of mental health services and promotion for youth.

\section{Ongoing Needs in Youth Mental Health}

Globally, youth engagement in mental health promotion and treatment is considered challenging. ${ }^{3}$ Low utilization rates, missed appointments, and the lack of youth-friendly services frequently affect program success and health outcomes. ${ }^{2}$ Clinicians and researchers around the world cite both social (e.g. socioeconomic status, public policies, or primary care availability) and individual (e.g. genetics or temperament) determinants that can influence accessibility and equity of youth mental health services ${ }^{3,9}$ In Canada, healthcare enlists eHealth services to improve access to vulnerable populations, such as videoconferencing with patients in remote communities. ${ }^{5}$ Provinces and territories are collaborating to leverage federal resources to implement electronic health systems and policies to expedite eHealth services within primary care. ${ }^{5}$ Similarly, a coordinated and national commitment to develop eHealth strategies is necessary to modernize Canadian youth mental health promotion and treatment.

Despite the need for reform, Canadian youth mental health accessibility remains relatively static. ${ }^{2}$ In recent years, there have been few instances of transformative innovation in Canadian healthcare. ${ }^{6}$ Canada's healthcare framework is grounded in both the Constitution Act of 1867 and the Canada Health Act. ${ }^{6}$ Furthermore, the current Canadian economic condition constrains the availability of resources necessary to support "big bang" or radical, nationwide transformation in mental health care. ${ }^{6}$ As such, incremental eHealth integration into Canadian youth mental health services is a realistic alternative to encourage nationwide changes. For example, eHealth can enable access to programs and can minimize costs by creating youth-friendly mental health mobile phone applications or utilizing social media in psychiatry to connect with outpatients (e.g., private Facebook messaging). The advancement of technology can be used to bridge the many gaps in the delivery of youth mental health services and promotion.

\section{Contributions of Technology}

With technological availability, mental health programs worldwide gradually embraced eHealth to aid in the delivery of an equitable and cost-effective youth mental health care system. The common delivery of eHealth services in many countries has been in partnership with primary care services, community services, or virtual clinics administered by specialists. ${ }^{7}$ For example, eHealth plays a role in Australia's mental health delivery by offering several free evidence-based online self-help psychotherapy services, such as MoodGYM and BluePages. ${ }^{8}$ These examples highlight opportunities in how eHealth could be used in Canada's youth mental health to improve health outcomes, extend services, and reduce hospital readmission 
c rates. $^{8}$ These eHealth services could potentially address

social determinants of health among young people.

eHealth programs have the potential to reduce mental health inequities experienced by youth. Internationally, researchers indicate that social factors, such as distribution of health resources or socioeconomic status, influence accessibility, equity, and health outcomes of these programs, as stated above. ${ }^{9}$ To tackle these social determinants, study findings show that universal schoolbased mental health programs, administered by teachers, assist in addressing health inequalities. ${ }^{10}$ These programs offer computer access to the entire student population in order to engage youth in online evidence-based modules; these modules help to overcome hardships and to connect the thoughts, feelings, and behaviours of youth. ${ }^{10}$ Conversely, this strategy fails to reach highly vulnerable youth, such as dropouts or the homeless. Therefore, schools, primary care facilities, and community services must work together to provide multiple routes to online youth-friendly mental health programs. Moreover, these youth may require alternative technology access, such as youth centre computers, Aboriginal community centres, public library Internet services, or mental health programs that loan mobile phones.

\section{Conclusions}

Technology provides an opportunity to engage youth because a significant number of young Canadians use online applications in their daily lives. The rapidly increasing - yet largely uncoordinated - demand for technological support related to the development and deployment of eHealth initiatives highlights the need for a national strategy to accomplish these goals. Presently, public health policies do not adequately focus on social determinants influencing health among youth. Decisions to integrate technology into youth mental health services need to be given careful attention and consideration; these decisions require policy direction. The resulting strategic integration of technology into these services will help improve accessibility and youth engagement in mental health promotion and treatment and, in so doing, will ensure that our youth attain the best quality of life possible.

\section{References}

1. World Health Organization. eHealth at WHO [Internet]. 2013 [cited 2011 Nov 7]. Available from: http://www.who.int/ehealth/about/en/

2. Canadian Mental Health Association. Youth mental health [Internet]. 2012 [cited 2013 Jan 15]. Available from: http://www.cmha.ca/mental-health/ your-mental-health/youth/

3. Tylee A, Haller DM, Graham T, Churchill R, Sanci LA. Youth-friendly primarycare services: How are we doing and what more needs to be done? Lancet. 2007; 369(9572):1565-73.

4. World Health Organization. Building foundations for eHealth [Internet]. 2006 [cited 2011 Nov 7]. Available from: http://www.who.int/goe/ publications/bf_FINAL.pdf

5. Canada Health Infoway. Progress in Canada [Internet]. 2012 [cited 2013 Mar 16]. Available from: https://www.infoway-inforoute.ca/index.php/ progress-in-canada

6. Hutchinson B, Abelson J, Lavis J. Primary care in Canada: So much innovation, so little change. Health Affairs. 2001;20(1):116-129.

7. Christensen $\mathrm{H}$, Hickie IB. E-mental health: A new era in delivery of mental health services [Internet]. Med. J. Aust. 2010 [cited 2013 Mar 25];192(11). Available from: https://www.mja.com.au/journal/2010/192/11/e-mentalhealth-new-era-delivery-mental-health-services

8. Australian Centre for Mental Health Research. E-health [Internet]. 2013 [cited 2013 Mar 25]. Available from: http://cmhr.anu.edu.au/research/ehealth

9. Viner RM, Ozer EM, Denny S, Marmot M, Resnick M, Fatusi A et al. Adolescence and the social determinants of health. The Lancet. 2012 Apr;379(9826):1641-52.

10. Spence SH, Sheffield JK, Donovan CL. Long-term outcome of a school-based, universal approach to prevention of depression in adolescents. J Consult Clin Psychol. 2005 Feb;73(1):160-7.

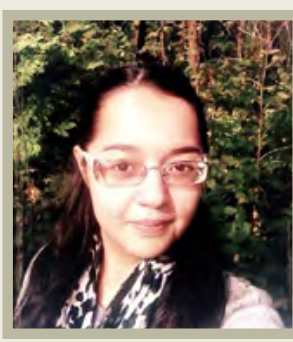

\section{Johanna Sam}

Johanna Sam is a proud member of Tl'Etinqox T'in Nation. She is currently completing her Master of Science degree in Population \& Public Health at the University of British Columbia. Her research project is guided by attachment theory to examine gender differences in the relationships between adverse childhood experiences and whether attachment style is related to ways in which youth access mental health services - especially mental health services that are being delivered or facilitated by new technology. Her interests involve new information and communication technology initiatives designed to enhance equity for socially marginalized populations, such as Indigenous people, youth, and women. 